\title{
The Effect of Ursodeoxycholic Acid on Biliary Bile Acid Composition in Patients with Gholesterol Gallstone
}

\author{
Yoshiniko Kanazawa, Masaru Koizumi, Hidetoshi Hirakawa, \\ Katsuhiro Endo, Shin Yoshida, Takatoshi Miyakawa, \\ Yasutoshi Konno, Yoshio Goto, Junichi Goto* and \\ TOShio Nambara* \\ Third Department of Internal Medicine, Tohoku University School \\ of Medicine, Sendai 980 and *Pharmaceutical Institute, Tohoku \\ University, Sendai 980
}

Kanazawa, Y., Koizumi, M., Hirakawa, H., Endo, K., Yoshida, S., Mryakawa, T., Konno, Y., Goto, Y., Goto, J. and Nambara, T. The Effect of Ursodeoxycholic Acid on Biliary Bile Acid Composition in Patients with Cholesterol Gallstone. Tohoku J. exp. Med., 1982, 136 (3), 235-249 — To elucidate the role of conjugated biliary bile acids in gallstone dissolution, the acids in bile were determined by high-performance liquid chromatography before and after the treatment with ursodeoxycholic acid for 3-26 months in patients with gallstone. The stone-dissolving effect of ursodeoxycholic acid was confirmed in 7 of 10 patients and the lithogenic index lowed significantly after the treatment. The compositions of cholate, chenodeoxycholate and ursodeoxycholate were about 33,45 and $4 \%$, respectively, in the control and pre-treatment groups. In the post-treatment group, a markedly low value was observed in primary bile acids both glycine-conjugates and taurine-conjugates, especially in cholate, with a significantly high value of ursodeoxycholate $(p<0.001)$ of both conjugates. On the other hand, no difference was observed in the composition of deoxycholate with significantly low percentage of taurine-conjugates compared with that in the pre-treatment group. The ratio of glycine- to taurine-conjugated bile acids showed a significantly higher value in the post-treatment group than in the pretreatment group $(p<0.001)$ and the control group $(p<0.005)$. The bile specimens were measured concomitantly by gas-liquid chromatography and the results were compared with those of high-performance liquid chromatography. The mean value of total bile acids, the ratio of cholate to chenodeoxycholate and the ratio of glycine- to taurine-conjugated bile acids obtained by the former analysis procedure represented about 57,80 and $115 \%$ of those of the latter. It is concluded that the high $\mathrm{G} / \mathrm{T}$ value seems to have a role in the dissolution mechanism. - bile acid; ursodeoxycholic acid; cholesterol gallstone; high-performance liquid chromatography; ratio of glycine- to taurine-conjugated bile acids ( $\mathrm{G} / \mathrm{T}$ ratio)

Since the dissolution of cholesterol gallstones by chenodeoxycholic acid (CDCA) (Bell et al. 1972; Danzinger et al. 1972) and ursodeoxycholic acid (UDCA) (Sugata and Shimizu 1974; Makino et al. 1975) was demonstrated, an attention has been

Received for publication, June 15, 1981. 
focused on the metabolism of bile acids in man in connection with the dissolution effect (Thistle and Hofmann 1973; Tokyo Cooperative Gallstone Study Group 1980) and its mechanism (Admirand and Small 1968; Danzinger et al. 1973; Fedorowski et al. 1977; Carey and Small 1978; Stiel et al. 1978, 1980).

Current methods for the determination of bile acids involve alkaline hydrolysis of the conjugates under drastic conditions followed by gas-liquid chromatographic (GLC) separation of liberated bile acids (Nakayama 1967; Iwabuchi 1978). This procedure, however, has inevitable disadvantages, viz. lack of reliability of the analytical results due to incomplete hydrolysis and formation of artifacts as well as the loss of information about the conjugate form of bile acids.

Recently, many attempts have been made to separate the bile acids by highperformance liquid chromatography (HPLC) without hydrolysis of conjugate form (Goto et al. 1978, 1980). Nevertheless, there have been no reports available on the application of this method for the determination of bile acids in patients with gallstone. The present paper describes the compositions of biliary glycine- and taurine-conjugated bile acids in gallstone patients before and after the administration of ursodeoxycholic acid (UDCA). A comparison of results obtained by GLC and HPLC methods is discussed.

\section{Materials and Methods}

Subjects

The subjects consisted of 17 patients, 5 males and 12 females, having asymptomatic radiolucent gallstones in well visualized functioning gallbladders. The age range was from 22 to 78 years. Sixteen patients were administered $600 \mathrm{mg} /$ day of UDCA and one patient $450 \mathrm{mg} /$ day. All patients continued taking their customary diet during the study, and no change in body weight was seen in any patient after the treatment. Table 1 shows the characteristics of 10 patients in whom the clinical effects of UDCA could be followed.

Bile specimens were obtained from 15 patients before, and from 7 patients after the administration of UDCA. In 5 of these patients bile samples were taken before and after the treatment. As the control subjects, 6 healthy volunteers (6 male, aged 18-23)

TABLE 1. Characteristics of the patients treated

\begin{tabular}{rccccccc} 
Patient & $\begin{array}{c}\text { Age } \\
\text { (years) }\end{array}$ & Sex & $\begin{array}{c}\text { Height } \\
(\mathrm{cm})\end{array}$ & $\begin{array}{c}\text { Weight } \\
(\mathbf{k g})\end{array}$ & $\begin{array}{r}\text { Relative BW } \\
(\%)\end{array}$ & $\begin{array}{c}\text { Dose } \\
(\mathrm{mg} / \text { day })\end{array}$ \\
\hline 1. & K.S. & 46 & F & 154 & 57 & 117.5 & 600 \\
2. & T.A. & 63 & F & 144 & 41 & 103.5 & 600 \\
3. N.O. & 25 & F & 162 & 55 & 98.6 & 600 \\
4. & I.M. & 67 & F & 152 & 50 & 106.8 & 600 \\
5. M.M. & 61 & F & 155 & 51 & 103.0 & 600 \\
6. N.S. & 61 & M & 160 & 53 & 98.1 & 600 \\
7. C.N. & 36 & F & 154 & 51 & 104.9 & 600 \\
8. & T.T. & 55 & F & 156 & 53 & 105.2 & 600 \\
9. T.O. & 60 & F & 157 & 57 & 111.1 & 450 \\
10. H.S. & 25 & M & 169 & 65 & 104.7 & 600
\end{tabular}

Relative BW, relative body weight $=\frac{\text { body weight } \times 100}{(\text { height }-100) \times 0.9}$ 
and 6 out-patients (4 male and 2 female, aged 36-45) without any gastrointestinal or liver diseases were included in the study.

All patients were informed about the conception of the study and oral consent was obtained.

After an overnight fast, subjects were intubated with a double lumen gastroduodenal tube (Yayoi Co., Tokyo) positioned under fluoroscopic control. $30 \mathrm{ng} / \mathrm{kg}$ of Caerulein was injected intravenously for $5 \mathrm{~min}$ to elicit the contraction of the gallbladder, and bile rich duodenal content was collected for $10 \mathrm{~min}$ by siphonage. This fluid was taken and stored at $-20^{\circ} \mathrm{C}$ until analysis.

\section{Instrument}

A gas-liquid chromatogram, Hitachi model 056 (Hitachi, Ltd., Tokyo), with a flame ionisation detector was used. The glass U-shaped column $(2 \mathrm{~m} \times 3 \mathrm{~mm}$ i.d. $)$ was packed with $0.18 \%$ Poly-I 110 on Chromosorb WHP (80-100 mesh). The apparatus used for HPLC was a Waters 6000A solvent delivery system (Waters Ass., Milford, Mass.) equipped with a Model Uvidec 100-II ultraviolet (UV) detector monitoring absorbance at $205 \mathrm{~nm}$. A Radial-Pak A column (10 cm $\times 8 \mathrm{~mm}$ i.d., Waters Ass.) was used under ambient conditions.

\section{Materials}

The unconjugated bile acids were purchased from Sigma Chemical Co. (St. Louis, Mo.) and purified prior to use. The glyco- and tauro-conjugates were synthesized by the p-nitrophenyl ester method in our laboratories. Estriol and UDCA were donated by Teikoku Hormone Mfg. Co. (Tokyo) and Tokyo Tanabe Co. (Tokyo), respectively. All the reagents were of analytical grade. The solvents were purified by distillation prior to use. The trimethylsilylating reagent (TMS-HT) which includes hexamethyldisilazane, trimethylchlorosilane and pyridine, and Sephadex LH-20 were supplied by Tokyo Kasei Co. (Tokyo) and Pharmacia Fine Chemicals (Uppsala), respectively. Piperidinohydroxypropyl Sephadex LH-20 (PHP-LH-20) and eluents used for ion-exchange gel chromatography were prepared in the manner previously reported (Goto et al. 1978). A Sep-pak C18 cartridge (Water Ass.) was washed successively with methanol $(10 \mathrm{ml})$, acetonitrile $(10 \mathrm{ml})$, and water $(10 \mathrm{ml})$ prior to use (Goto et al. 1980).

Procedure for determination of bile acids in human bile

The analysis of bile acids with GLC was carried out by the method of Okawa et al. (1976) with a minor modification (Iwabuchi 1978). After extracting $0.1 \mathrm{ml}$ of duodenal bile with 20 -fold ethanol and removing neutral sterol with n-hexane, test samples were subjected to alkaline hydrolysis followed by derivatization with diazomethane and TMS-HT to form TMS ether-methylesters, and then injected into GLC. Temperature of the injector and detector was $260^{\circ} \mathrm{C}$. The flow rate of $\mathrm{He}$ was $60 \mathrm{ml} / \mathrm{min}$. On this condition

with $U D C A$ and the efficacy of $U D C A$

\begin{tabular}{rrlll}
$\begin{array}{c}\text { Duration } \\
(\text { month })\end{array}$ & $\begin{array}{c}\text { Number of } \\
\text { stones }\end{array}$ & $\begin{array}{c}\text { Size of stone } \\
(\mathrm{mm})\end{array}$ & Floating & Dissolved effect \\
13 & 1 & $13 \times 15$ & $(-)$ & Smaller \\
12 & 2 & $4 \times 6,5 \times 7$ & $(-)$ & Dissolved \\
10 & 2 & $2 \times 3,7 \times 9$ & $(-)$ & Dissolved \\
5 & $>10$ & $1.5 \cdots 3$ & $(+)$ & Dissolved \\
28 & $>10$ & $4 \times 4 \cdots 14 \times 15$ & $(-)$ & Dissolved \\
12 & 1 & $15 \times 22$ & $(-)$ & Unchanged \\
10 & $>10$ & $2 \times 3 \cdots 3 \times 4$ & $(+)$ & Dissolved \\
3 & $>10$ & $3 \times 3 \cdots 5 \times 6$ & $(+)$ & Smaller \\
6 & 3 & $7 \times 10 \cdots 15 \times 21$ & $(-)$ & Unchanged \\
6 & 1 & $12 \times 17$ & $(-)$ & Unchanged \\
\hline
\end{tabular}


$5 \beta$-cholanic acid as an internal standard appeared at $12 \mathrm{~min}$ and each bile acids were efficiently resolved.

Group separation into free, glycine- and taurine-conjugated bile acids which were submitted to GLC was also achieved by thin-layer chromatography (TLC), as described in the previous papers (Hofmann 1962; Iwabuchi 1968).

The analysis of bile acids with HPLC was carried out by the method previously reported (Goto et al. 1978, 1980). The general procedure for determination of bile acids in human bile is shown in Fig. 1. A bile sample $(10 \mu \mathrm{l})$ was submitted to clean-up using Sep-pak C18 cartridge and PHP-LH-20 and then to HPLC. The amount of each bile acid was determined by the calibration curve constructed by plotting the ratio of peak area of bile acid to that of estriol against the weight of bile acid. Fig. 2 shows a typical chromatogram of the glycine-conjugated fraction in human bile processed as described above. Lithocholate was not detected on the chromatogram in this specimen.

Total cholesterol was measured by Naka's method (1972), and phospholipids were assayed as inorganic phosphorus according to Bartlett's procedure (1959).

Lipid composition of bile was expressed as a "lithogenic index" and calculated from

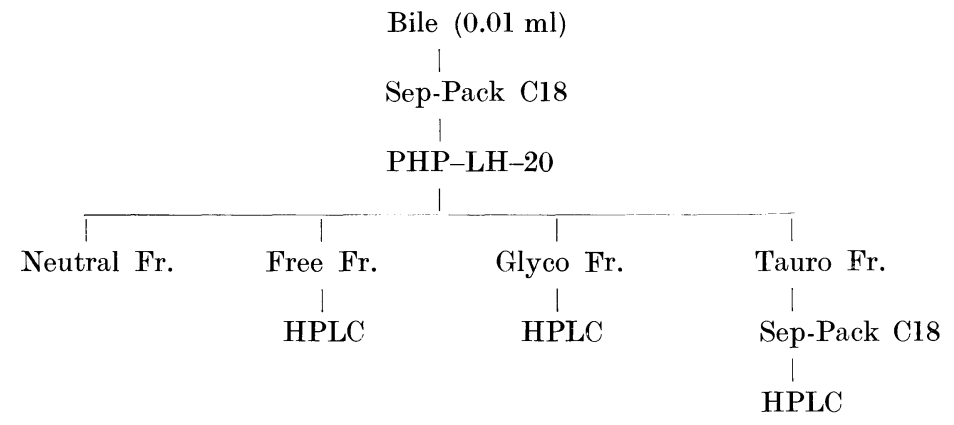

Fig. 1. Flow diagram for determination of bile acids in human bile with high performance liquid chromatography.

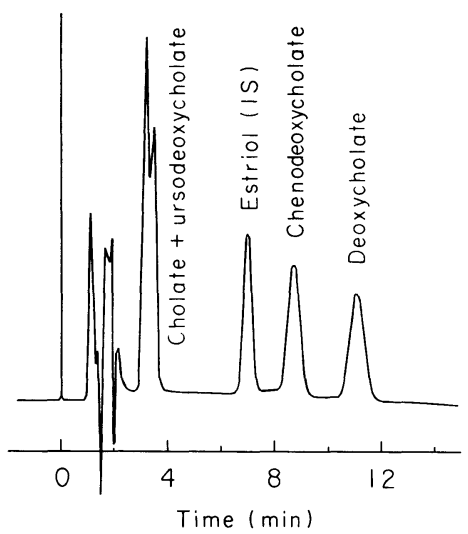

b

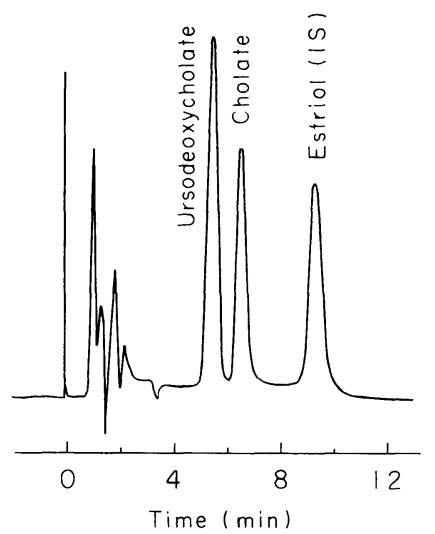

Fig. 2. Separation of glycine-conjugated bile acids in human bile by HPLC. Conditions: Radial-Pak A column; detection, ultraviolet $(205 \mathrm{~nm})$; mobile phase, (a) $0.3 \%$ ammonium phosphate (pH 7.7)/acetonitrile (19:8, v/v), $2 \mathrm{ml} / \mathrm{min}$; (b) $0.3 \%$ ammonium phosphate $(\mathrm{pH} 7.7) /$ acetonitrile $(23: 8, \mathrm{v} / \mathrm{v}), 2 \mathrm{ml} / \mathrm{min}$. 
polynomial equation (Thomas and Hofmann 1973) describing the cholesterol solubility line proposed by Admirand and Small (1968).

\section{Statistical analysis}

All results were expressed as mean values with standard deviations of the mean. The statistical significance of differences between means was estimated using non-paired Student's $t$-test.

\section{Results}

Comparison of analytical results obtained by GLC and HPLC methods

Comparison of the total amount of bile acids for 25 bile specimens between GLC and HPLC is shown in Fig. 3. An obvious relationship was observed. Each value measured by GLC was lower and represented only $57 \%$ of that by HPLC. The ratios of cholate to chenodeoxycholate $(\mathrm{C} / \mathrm{CDC})$ and glycine- to taurine-conjugates $(\mathrm{G} / \mathrm{T})$ in the two methods were then compared. The results are shown in Figs. 4 and 5. HPLC showed about a 20\% higher C/CDC value and a slightly lower G/T value.

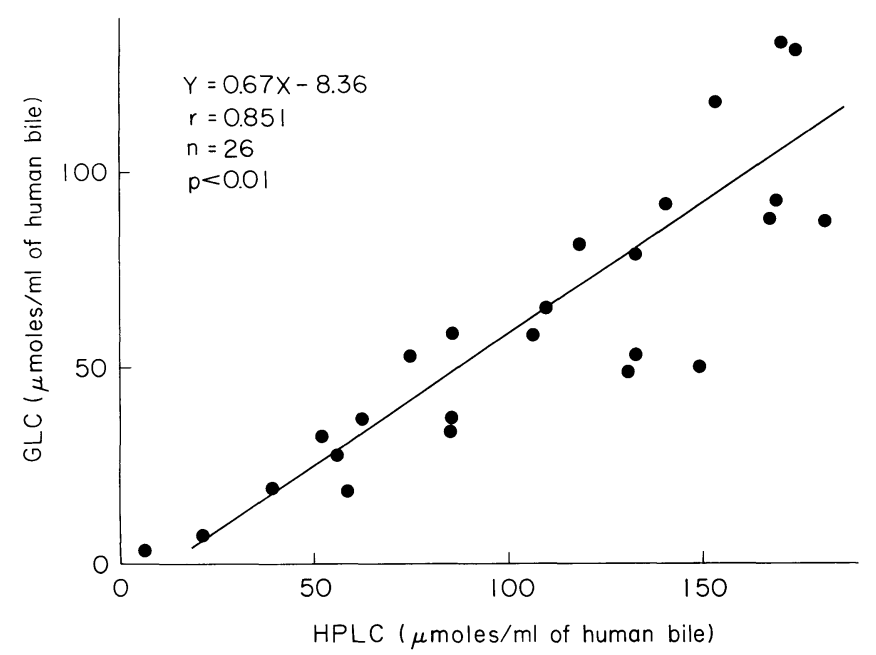

Fig. 3. Comparison of total bile acid obtained with high performance liquid chromatography (HPLC) and gas liquid chromatography (GLC).

\section{Effect of UDCA on gallstone patients}

Examination was made on the dissolution effect of UDCA administration in 10 patients. The complete dissolution of gallstones was observed in 5 patients and the incomplete effect, diminishing of the stone size, was seen in 2 patients. During the UDCA treatment, no change was observed in liver function tests or in the values of fasting serum cholesterol or triglyceride. Neither did the administration of UDCA cause any symptoms, e.g. nausea, abdominal pain, nor symptoms of gastrointestinal irritation including diarrhea. 


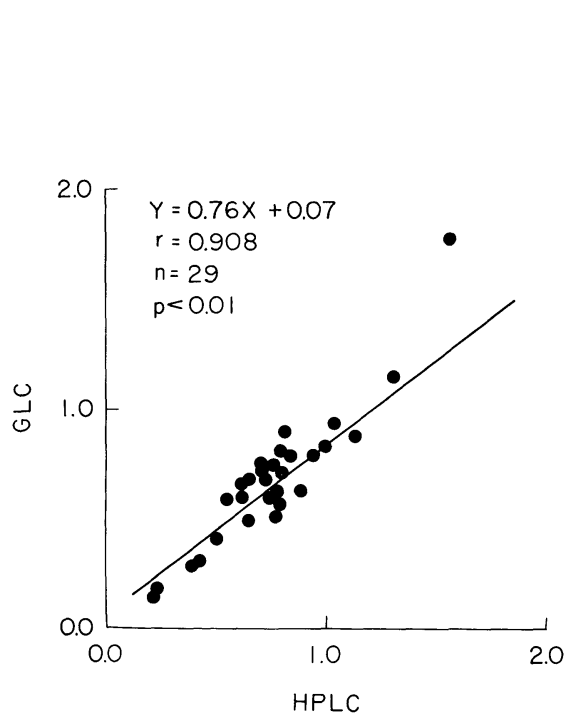

Fig. 4

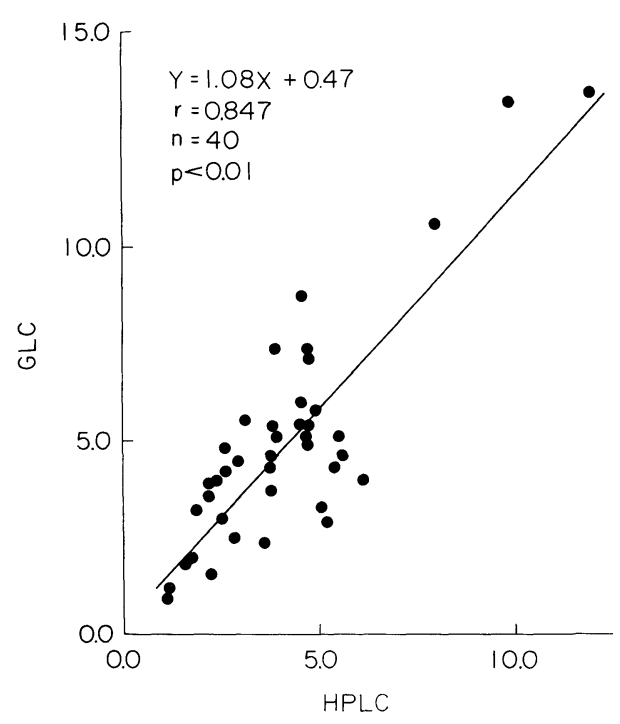

Fig. 5

Fig. 4. Comparison of $\mathrm{C} / \mathrm{CDC}$ values obtained with high performance liquid chromatography (HPLC) and gas liquid chromatography (GLC).

Fig. 5. Comparison of the ratio of glycine- to taurine-conjugated bile acids obtained with high performance liquid chromatography (HPLC) and gas liquid chromatography (GLC).

Determination of bile acids in patients with gallstone

The lithogenic index lowered significantly in the post-trestment group $(0.59 \pm$ $0.14)$ as compared with the pre-treatment group $(1.18 \pm 0.71)$. Changes of lithogenic index in 5 patients with gallstone by the administration of UDCA are shown in Fig. 6 .

Biliary bile acid compositions in the control, pre-treatment and posttreatment groups determined by HPLC are shown in Tables 2, 3 and 4, and in Figs. $7,8,9,10,11$ and 12 .

No differences were observed in any bile acid composition or in $\mathrm{C} / \mathrm{CDC}$ or $\mathrm{G} / \mathrm{T}$ ratio between controls and pre-treatment group. However, in the post-treatment group, significantly lower percentages of primary bile acids, both glycine-conjugates

TABLE 2. Biliary bile acid composition in the control group

\begin{tabular}{lcccccc} 
& $\begin{array}{c}\mathrm{C} \\
(\% \text { moles })\end{array}$ & $\begin{array}{c}\mathrm{CDC} \\
(\% \text { moles })\end{array}$ & $\begin{array}{c}\text { DC } \\
(\% \text { moles })\end{array}$ & $\begin{array}{c}\text { LC } \\
(\% \text { moles })\end{array}$ & $\begin{array}{c}\text { UDC } \\
(\% \text { moles })\end{array}$ & C/CDC \\
\hline Total conjugates & $34.7 \pm 8.0$ & $45.0 \pm 10.6$ & $16.1 \pm 11.0$ & $0.1 \pm 0.2$ & $4.1 \pm 3.4$ & $0.83 \pm 0.30$ \\
Glycine-conjugates & $27.2 \pm 8.0$ & $33.2 \pm 5.8$ & $13.5 \pm 9.4$ & $0.1 \pm 0.2$ & $3.6 \pm 3.3$ & $0.85 \pm 0.31$ \\
Taurine-conjugates & $7.5 \pm 2.4$ & $11.8 \pm 7.5$ & $2.6 \pm 2.0$ & - & $0.4 \pm 0.9$ & $0.74 \pm 0.25$ \\
Glycine/Taurine & $4.03 \pm 1.67$ & $3.52 \pm 1.47$ & $5.35 \pm 2.84$ & - & $9.77 \pm 6.40$ &
\end{tabular}

Mean \pm S.D. $(n=12)$.

C, cholate; CDC, chenodeoxycholate; DC, deoxycholate; LC, lithocholate; UDC, ursodeoxycholate. 
TABLE 3. Biliary bile acid composition in the pre-treatment group

$\begin{array}{lcccccc} & \begin{array}{c}\mathrm{C} \\ (\% \text { moles })\end{array} & \begin{array}{c}\mathrm{CDC} \\ (\% \text { moles })\end{array} & \begin{array}{c}\mathrm{DC} \\ (\% \text { moles })\end{array} & \begin{array}{c}\mathrm{LC} \\ (\% \text { moles })\end{array} & \begin{array}{c}\text { UDC } \\ (\% \text { moles })\end{array} & \mathrm{C} / \mathrm{CDC} \\ & & & & & \\ \text { Total conjugates } & 32.2 \pm 5.7 & 45.0 \pm 11.1 & 18.0 \pm 9.1 & 0.3 \pm 0.6 & 4.5 \pm 3.8 & 0.76 \pm 0.24 \\ \text { Glycine-conjugates } & 23.4 \pm 5.0 & 32.3 \pm 8.9 & 14.7 \pm 8.4 & 0.3 \pm 0.6 & 3.5 \pm 3.1 & 0.78 \pm 0.29 \\ \text { Taurine-conjugates } & 8.7 \pm 3.7 & 12.7 \pm 6.1 & 3.3 \pm 1.6 & - & 1.0 \pm 1.1 & 0.78 \pm 0.38 \\ \text { Glycine/Taurine } & 3.31 \pm 2.10 & 3.32 \pm 2.40 & 4.96 \pm 3.59 & - & 5.71 \pm 4.49 & \end{array}$

Mean \pm s.D. $(n=15)$.

C, cholate; CDC, chenodeoxycholate; DC, deoxycholate; LC, lithocholate; UDC, ursodeoxycholate.

TABLE 4. Biliary bile acid composition in the post-treatment group

\begin{tabular}{lcccccc} 
& $\begin{array}{c}\mathrm{C} \\
(\% \text { moles })\end{array}$ & $\begin{array}{c}\text { CDC } \\
(\% \text { moles })\end{array}$ & $\begin{array}{c}\text { DC } \\
(\% \text { moles })\end{array}$ & $\begin{array}{c}\text { LC } \\
(\% \text { moles })\end{array}$ & $\begin{array}{c}\text { UDC } \\
(\% \text { moles })\end{array}$ & C/CDC \\
\hline Total conjugates & $13.0 \pm 5.5$ & $26.1 \pm 3.9$ & $17.6 \pm 8.3$ & $1.5 \pm 2.5$ & $41.8 \pm 13.6$ & $0.51 \pm 0.23$ \\
Glycine-conjugates & $10.6 \pm 4.7$ & $22.3 \pm 4.5$ & $16.2 \pm 7.6$ & $1.5 \pm 2.5$ & $37.6 \pm 13.4$ & $0.50 \pm 0.27$ \\
Taurine-conjugates & $2.4 \pm 1.7$ & $3.8 \pm 1.8$ & $1.5 \pm 1.5$ & - & $4.2 \pm 3.1$ & $0.60 \pm 0.27$ \\
Glycine/Taurine & $6.34 \pm 3.88$ & $7.89 \pm 4.98$ & $19.75 \pm 16.99$ & - & $13.58 \pm 8.62$ &
\end{tabular}

Mean士s.D. $(n=7)$.

C, cholate; CDC, chenodeoxycholate; DC, deoxycholate; LC, lithocholate; UDC, ursodeoxycholate.

Fig. 6. Comparison of lithogenic index between the pre-treatment group (Pr) and post-treatment group (Po), including 5 patients whose biles were analyzed both before and after treatment.

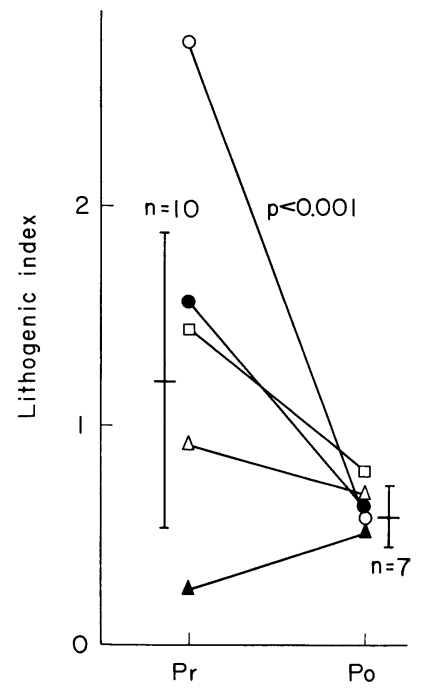

and taurine-conjugates, were obtained than those in the control and pre-treatment groups; especially the $\mathrm{C} / \mathrm{CDC}$ ratio lowered markedly. Significantly high percentages of both conjugated ursodeoxycholate were obtained in the post-treatment group.

No difference was observed in the deoxycholate (DC) composition between the post-treatment group and the other groups. UDCA administration induced a significant difference in $\mathrm{G} / \mathrm{T}$ ratio of $\mathrm{C}, \mathrm{CDC}, \mathrm{DC}$ and UDC as compared with those in the pre-treatment group and induced a significantly high value of $\mathrm{G} / \mathrm{T}$ ratio only 


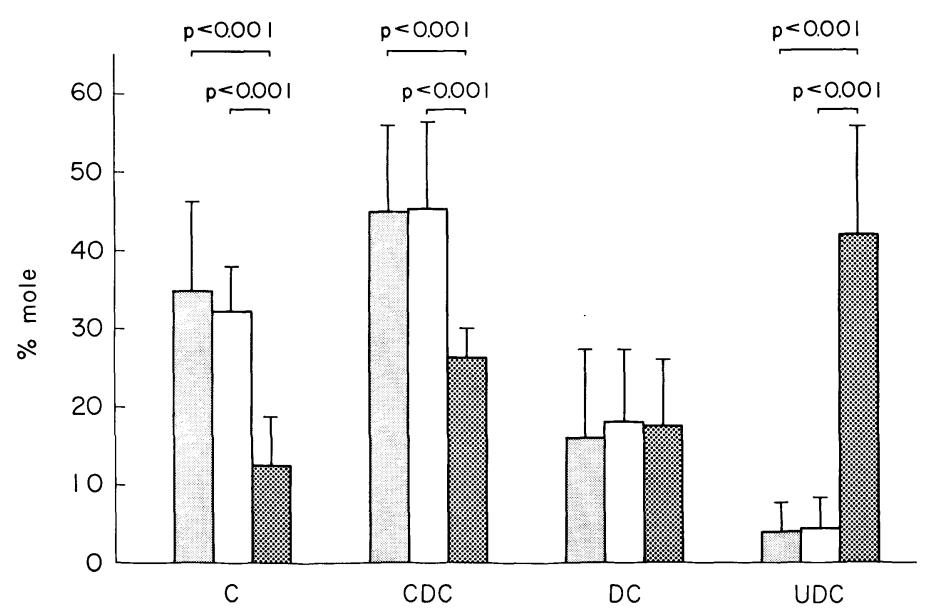

Fig. 7. Comparison of biliary bile acids in the control (\%), pre-treatment $(\square)$ and post-treatment group. C, cholate; CDC, chenodeoxycholate; DC, deoxycholate; UDC, ursodeoxycholate.

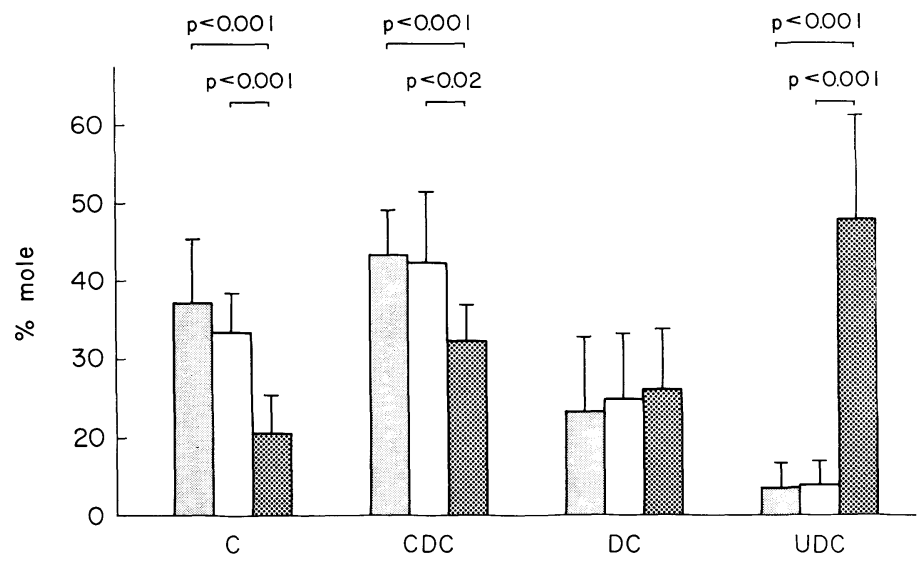

Fig. 8. Comparison of biliary glycine-conjugated bile acids in the control ( $\leftrightarrow$ ), pretreatment $(\square)$ and post-treatment ( groups. C, cholate; CDC, chenodeoxycholate; DC, deoxycholate; UDC, ursodeoxycholate.

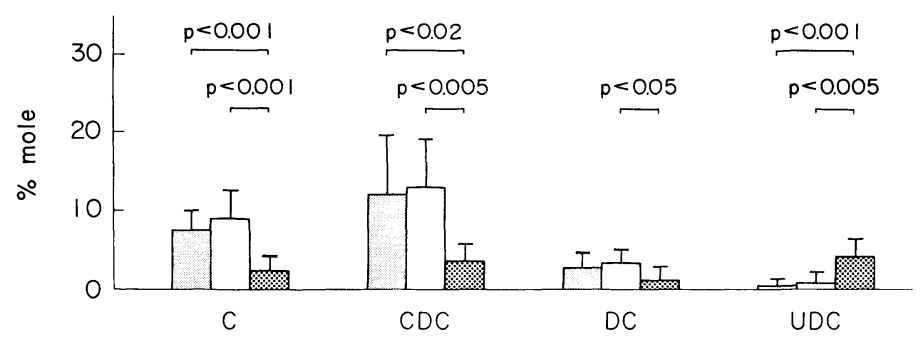

Fig. 9. Comparison of biliary taurine-conjugated bile acids in the control (\%०), pretreatment ( $\square$ ) and post-treatment groups. C, cholate; CDC, chenodeoxycholate; DC, deoxycholate; UDC, ursodeoxycholate. 


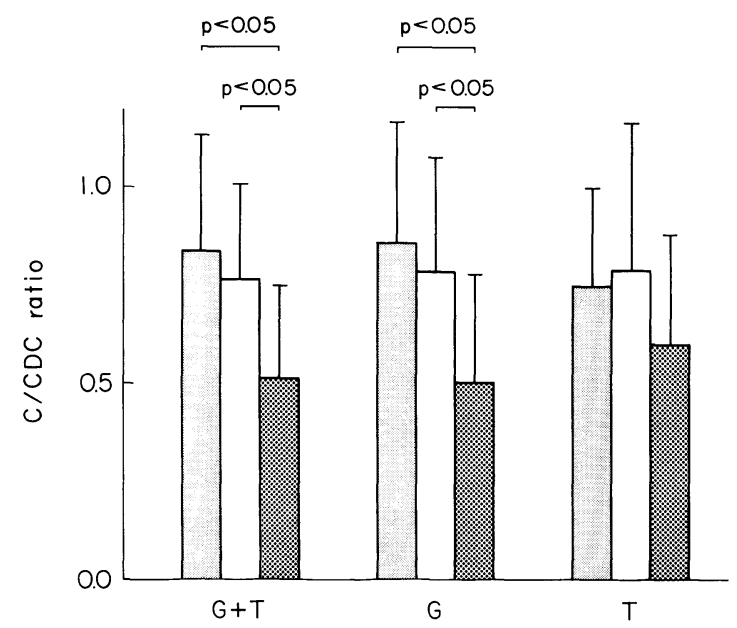

Fig. 10. Comparison of the cholate to chenodeoxycholate ratio (C/CDC) in the control (\%), pre-treatment $(\square)$ and post-treatment ( jugates puls taurine-conjugates, $\mathrm{G}$, glycine-conjugates; $\mathrm{T}$, taurine-conjugates.

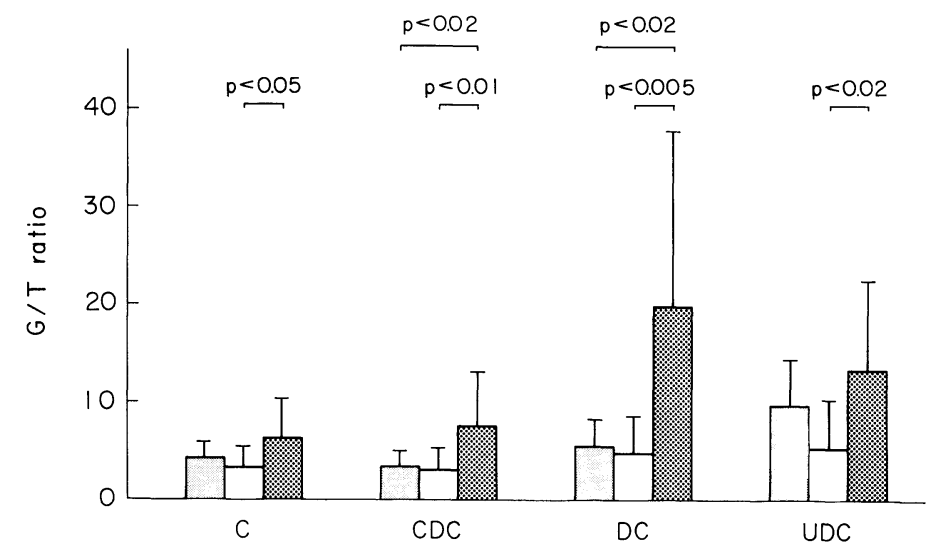

Fig. 11. Comparison of the glycine/taurine ratio ( $\mathrm{G} / \mathrm{T}$ ratio) in each bile acid in the control (ख), pre-treatment $(\square)$ and post-treatment (口roups. C, cholate; CDC, chenodeoxycholate; DC, deoxycholate; UDC, ursodeoxycholate.

in CDC and DC, as compared with those in the control group.

Total G/T ratio showed a significantly high value in post-treatment group $(9.1 \pm 4.7)$ as compared with both pre-treatment group $(3.5 \pm 1.9)(p<0.001)$ and the control group $(4.1 \pm 1.8)(p<0.005)$ (Fig. 12).

\section{Discussion}

In the present study, the determination of bile acids in human bile was performed by utilizing both GLC and HPLC. The total bile acid value measured by GLC was about $40 \%$ lower than that by HPLC. 


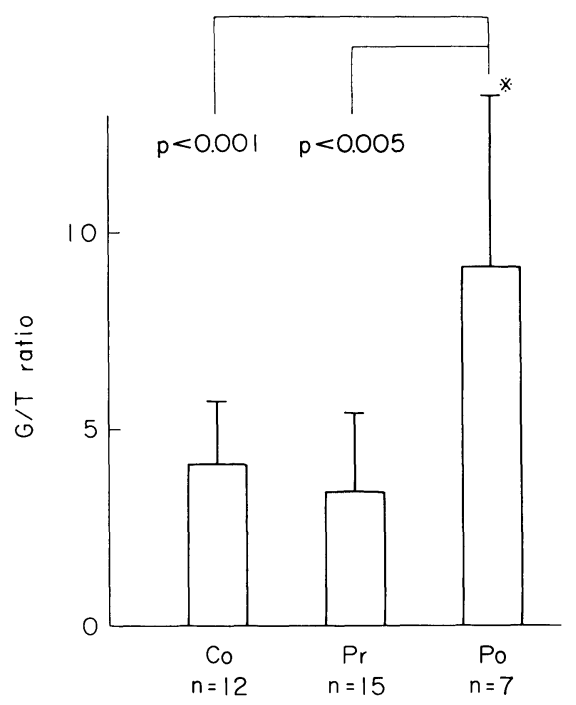

Fig. 12. Comparison of the total glycine/ taurine ratio $(\mathrm{G} / \mathrm{T}$ ratio) in the control $(\mathrm{Co})$, pre-treatment $(\mathrm{Pr})$ and posttreatment $(\mathrm{Po})$ groups.

A few bile samples were determined by using $3 \alpha$-hydroxy steroid dehydrogenase

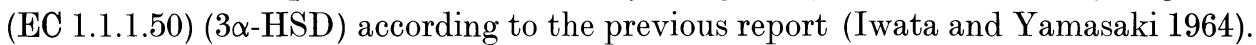
Since the levels determined by HPLC and $3 \alpha$ HSD were similar, it seems that much bile acid was lost during hydrolysis and/or extraction with ether by GLC.

Since cholic acid (CA) has tri-hydroxyl groups in the molecule and is more polar than other di- and mono-hydroxylated bile acids, it is supposed that the recovery of this compound is lower than other bile acids in the extraction step and the $\mathrm{C} / \mathrm{CDC}$ ratio becomes lower in GLC than in HPLC. It is known that taurineconjugates are more strongly adsorbed on silica gel and the extraction of these conjugates from the support results in difficulty. On the other hand, PHP-LH-20, a lipophilic gel, shows no difference in recovery of glycine- and taurine-conjugates because the conjugates are separated by ion exchange chromatography. Consequently, the higher $\mathrm{G} / \mathrm{T}$ ratio in GLC is observed.

These results show that HPLC is more suitable for the determination of bile acids in biological fluids and may provide more precise knowledge on the metabolic profile of bile acids in patients with gallstone.

The dissolving percentage of UDCA in this study was higher than $40 \%$ in the case of non-calcified stones and about $80 \%$ in non-calcified floating and mediumsized stones reported by the Tokyo Cooperative Gallstone Study Group (1980).

Although many studies were reported from the viewpoint of bile acid pool size (Fedorowski et al. 1977; Mok et al. 1977; Roda et al. 1979; Salvioli and Salati 1979) and of cholesterol and bile acid synthesis (Maton et al. 1977; Maton and Dowling 1979), the dissolution mechanism by UDCA is still unclear.

Our findings showed HPLC to be a more useful method for examining bile specimens of patients with cholesterol gallstone. The high value of UDC and the low values of cholate and CDC obtained in this study are in agreement with 
previous reports (Fedorowski et al. 1977; Makino and Nakagawa 1978; Stiehl et al. 1978).

Igimi et al. (1977) and Carey and Ko (1979) reported that UDC-conjugates may decrease cholesterol solubility and Raicht et al. (1974) suggested that cholateconjugates may help cholesterol absorption in rats. Based on these reports Ponz de Leon et al. (1980) speculated that UDCA administration induces a high UDC percentage and a low cholate percentage in biliary bile acids, and causes a decrease of dietary cholesterol absorption along with the presence of a large amount of unconjugated bile acid which could also interfere with the solubilization of cholesterol. Consequently the cholesterol absorption reduced by UDCA administration (Ponz de Leon et al. 1980) may cause a reduction of the hepatic cholesterol secretion (Scherstén and Lindblad 1979) and a decrease of lithogenic index (Maton et al. 1977; Makino and Nakagawa 1978; Ponz de Leon et al. 1980), since only a small fraction of the biliary cholesterol is newly synthesized in the liver and the major proportion is derived from lipoprotein cholesterol (Schwartz et al. 1978). Furthermore, dietary cholesterol could be responsible for inducing a supersaturated bile (DenBesten et al. 1973).

On the other hand, though UDC has lower solubility of cholesterol than other bile acids (Igimi et al. 1977; Carey and Ko 1979) and the percentage of UDC in biliary bile acid composition increases with the administration of UDCA (Makino and Nakagawa 1978), UDCA treatment causes a dissolution of cholesterol gallstone in human, and in regard of this mechanism Corrigan et al. (1980) proposed a new theory stating that mesophase formation and dispersion may occur during gallstone dissolution in the gallbladder of patients receiving UDCA.

A significantly lower $\mathrm{C} / \mathrm{CDC}$ ratio is presented in the post-treatment group than in the other two groups, i.e. the percentage of cholate is lower than that of CDC in the two primary bile acids which are reduced by UDCA administration. Therefore it is also possible to consider that a part of CDC is transformed from UDCA directly (Fedorowski et al. 1979) by intestinal bacteria or by liver enzyme following dehydration with intestinal bacteria (Fedorowski et al. 1977; Fromm et al. 1977). At the same time newly synthesized lithocholate from CDC in the intestine may be excreted into feces or may be detoxified by sulfation in the human liver (Allan et al. 1975).

In the present study no difference was observed in the deoxycholate (DC) composition between the post-treatment group and the other groups. Many authors have reported that the deoxycholate composition decreased by the administration of UDCA (Fedorowski et al. 1977; Makino and Nakagawa 1978; Stiehl et al. 1978; Roda et al. 1979; Ponz de Leon et al. 1980). It is clear that this difference is not dependent on the analytical method since the bile acid compositions in the control or pre-treatment groups of this study are in agreement with those of the pre-treatment group in other reports (Fedorowski et al. 1977; Makino and Nakagawa 1978; Stiehl et al. 1978; Roda et al. 1979; Ponz de Leon et al. 1980). Higher DC concentrations in biliary bile acids are reported to be beneficial 
to the cholesterol gallstone dissolution, since DC has higher cholesterol solubility than other bile acids (Hegardt and Dam 1971). The absence of the decrease in the mole percentage in this study may be considered as follows: CDCA treatment is often accompanied with diarrhea which is less frequent under UDCA treatment (Maton et al. 1977). At equimolar concentrations, CDCA induced a more marked inhibitory effect on the colonic absorption of water, sodium and oxalate in the rat (Caspary and Meyne 1980). Debongnie and Phillips (1977) observed that, in humans, under continuous infusion of isotonic solution into caecum, CDC feeding impaired colonic compensation, and UDC feeding did not reduce the capacity of the colon to handle a saline load at all. On the basis of these reports, it is thought that UDCA has only the same stimulation of colonic function as saline feeding has and that the motility of the intestine may be less stimulated by UDCA than CDCA which may stimulate the motility because of the increased intraluminal content (Debongnie and Phillips 1977; Caspary and Meyne 1980). The transit time of intestinal content may not be so shortened by UDCA feeding as compared with no feeding in the colon which is possibly one of the DC producing sites by intestinal bacteria (Miettinen and Peltokallio 1971; Percy-Robb et al. 1971). Consequently mole percent of DC was not changed.

Burnett (1965) reported a slightly lower G/T ratio in patients with gallstone. Our results showed a similar tendency in the pre-treatment group and a significantly higher ratio in the post-treatment group.

Excess conjugation of bile acids may produce a low percentage of taurineconjugates in the biliary bile acid composition (Danzinger et al. 1973; Hardison 1978). The administered UDCA, absorbed at a rate of about $90 \%$ in the intestine (Fedorowski et al. 1977), demands the conjugation along with the endogenous bile acids, and may produce a high G/T ratio (Stiehl et al. 1980; Kanazawa et al. 1980). The $\mathrm{G} / \mathrm{T}$ ratio of $\mathrm{DC}$ is higher than that of the primary bile acids which may be less synthesized in the feed back mechanism by UDCA because of free form of DC which is transformed from cholate with deconjugation and dehydration by intestinal bacteria. This study indicates that the high $\mathrm{G} / \mathrm{T}$ ratio could play a role in the dissolution mechanism in consideration of previous reports presenting higher solubility of cholesterol in glycine-conjugates than that in taurine-conjugates (Earnest and Admirand 1971; Hegardt and Dam 1971).

In the present study, no difference of $\mathrm{DC}$ and a significantly high value of $\mathrm{G} / \mathrm{T}$ ratio were observed in gallstone patients with the administration of UDCA. However, since the transformation of cholate to deoxycholate is dependent on intestinal bacteria, the relationship between deoxycholate composition and UDCA administration is not clear.

To elucidate the dissolution mechanism, further studies must be done from all angles and more precise knowledge of bile acid metabolism is needed. Highperformance liquid chromatography will provide valuable information for this purpose. 


\section{References}

1) Admirand, W.H. \& Small, D.M. (1968) The physicochemical basis of cholesterol gallstone formation in man. J. clin. Invest., 47, 1043-1052.

2) Allan, R.N., Gadacz, T.R., Mack, E. \& Hofmann, A.F. (1975) Impaired lithocholate sulfation in the rhesus monkey: a mechanism for chenodeoxycholate toxicity. Gastroenterology, 69, 802. (Abstract)

3) Bartlett, G.R. (1959) Phosphorus assay in column chromatography. J. biol. Chem., 234, 466-468.

4) Bell, G.D., Whitney, B. \& Dowling, R.H. (1972) Gallstone dissolution in man using chenodeoxycholic acid. Lancet, 2, 1213-1216.

5) Burnett, W. (1965) The pathogenesis of gallstones. In: The Biliary System, edited by W. Taylor, Oxford, Blackwell, pp. 601-618.

6) Carey, M.C. \& Ko, G. (1979) The importance of total lipid concentration in determining cholesterol solubility in bile and the development of critical tables for calculating 'percent cholesterol saturation' with a correction factor for ursodeoxy-cholate-rich bile. In: Biological Effects of Bile Acids, edited by G. Paumgartner, A. Stiehl \& W. Gerok, MTP Press, Lancaster, England, pp. 299-308.

7) Carey, M.C. \& Small, D.M. (1978) The physical chemistry of cholesterol solubility in bile. Relationship to gallstone formation and dissolution in man. J. clin. Invest., 61, 998-1026.

8) Caspary, W.F. \& Meyne, K. (1980) Effects of chenodeoxy- and ursodeoxycholic acid on absorption, secretion and permeability in rat colon and small intestine. Digestion, 20, 168-174.

9) Corrigan, O.I., Su, C.C., Higuchi, W.I. \& Hofmann, A.F. (1980) Mesophase formation during cholesterol dissolution in ursodeoxycholate-lecithin solution. New mechanism for gallstone dissolution in humans. J. pharm. Sci., 69, 869-870.

10) Danzinger, R.G., Hofmann, A.F., Schoenfield, L.J. \& Thistle, J.L. (1972) Dissolution of cholestrol gallstones by chenodeoxycholic acid. New Engl. J. Med., 286, $1-8$.

11) Danzinger, R.G., Hofmann, A.F., Thistle, J.L. \& Schoenfield, L.J. (1973) Effect of oral chenodeoxycholic acid on bile acid kinetics and biliary lipid composition in women with cholelithiasis. J. clin. Invest., 52, 2809-2821.

12) Debongnie, J.C. \& Phillips, S.F. (1977) Colonic function and diarrhea. Gastroenterology, 72, 1046. (Abstract)

13) DenBesten, L., Connor, W.E. \& Bell. S. (1973) The effect of dietary cholesterol on the composition of human bile. Surgery, 73, 266-273.

14) Earnest, D.E. \& Admirand, W.H. (1971) The effects of individual bile salts cholesterol solubilization and gallstone dissolution. Gastroenterology, 60, 772. (Abstract)

15) Fedorowski, T., Salen, G., Colallilo, A., Tint, G.S., Mosbach, E.H. \& Hall, J.C. (1977) Metabolism of ursodeoxycholic acid in man. Gastroenterology, 73, 1131-1137.

16) Fedorowski, T., Salen, G., Tint, G.S. \& Monsbach, E. (1979) Transformation of chenodeoxycholic acid and ursodeoxycholic acid by human intestinal bacteria. Gastroenterology, 77, 1068-1073.

17) Fromm, H., Farivar, S., Carlson, G.L., Hofmann, A.F. \& Amin, P. (1977) Hepatic formation of ursodeoxycholic and chenodeoxycholic acid from 7-ketolithocholic acid in man. Gastroenterology, 73, 1221. (Abstract)

18) Goto, J., Hasegawa, M., Kato, H. \& Nambara, T. (1978) A new method for simultaneous determination of bile acids in human bile without hydrolysis. Clin. chim. Acta. 87, 141-147.

19) Goto, J., Kato, H., Saruta, Y. \& Nambara, T. (1980) Separation and determination of bile acids in human bile by high-performance liquid chromatography. J. Liquid Chromatogr., 3, 991-1003.

20) Hardison, W.G. (1978) Hepatic taurine concentration and dietary taurine as regulators of bile acid conjugation with taurine. Gastroenterology. 75, 71-75. 
21) Hegardt, F.G. \& Dam, H. (1971) The solubility of cholesterol in aqueous solution of bile salts and lecithin. Z. Ernährungsw., 10, 223-233.

22) Hofmann, A.F. (1962) Thin-layer adsorption chromatography of free and conjugated bile acids on silicic acid. J. Lipid Res., 3, 127-128.

23) Igimi, H., Tamesue, N. Ikejiri, Y. \& Shimura, H., (1977) Ursodeoxycholate - in vitro cholesterol solubility and changes of composition of human gallbladder bile after oral treatment. Life Sci., 21, 1373-1380.

24) Iwabuchi, J. (1978) Composition of bile acids in cases with various gastrointestinal diseases. Jpn. J. Gastroent., 75, 869-881. (in Japanese with English abstract)

25) Iwata, T. \& Yamasaki, K. (1964) Enzymatic determination and thin-layer chromatography of bile acids in blood. J. Biochem., 56, 424-431.

26) Kanazawa, Y., Koizumi, M., Hirakawa, H., Endo, K., Yoshida, S., Goto, Y., Goto, J. \& Nambara, T. (1980) The effect of ursodeoxycholic acid on biliary bile acid composition in patients with cholesterol gallstone. Proc. Symp. chem. Physiol. Path., 20, 119-120. (Japanese)

27) Makino, I. \& Nakagawa, S. (1978) Changes in biliary lipid and biliary bile acid composition in patient after administration of ursodeoxycholic acid. J. Lipid Res., 19, 723728.

28) Makino, I., Shinozaki, K., Yoshino, K. \& Nakagawa, S. (1975) Dissolution of cholesterol gallstone by ursodeoxycholic acid. Jpn. J. Gastroent., 72, 690-702. (in Japanese with English abstract)

29) Maton, P.N., \& Dowling, R.H. (1979) Hepatic cholesterol synthesis in cholelithiasis. Role of HMG CoA reductase in response to resistance to medical therapy. In: Biological Effects of Bile Acids, edited by G. Paumgartner, A. Stiehl \& W. Gerok, MTP Press, Lancaster, England, pp. 91-98.

30) Maton, P.N., Murphy, G.M. \& Dowling, R.H. (1977) Ursodeoxycholic acid treatment of gallstones: Dose-response study and possible mechanism of action. Lancet, 2, 12971301.

31) Miettinen, T.A. \& Peltokallio, P. (1971) Bile salt, fat, water and vitamin B12 excretion after ileostomy. Scand. J. Gastroent., 6, 543-552.

32) Mok, H.Y., Von Bergmann, K. \& Grundy, S.M. (1977) Regulation of pool size of bile acids in man. Gastroenterology, 73, 684-690.

33) Naka, H. (1972) Serum cholesterol determination with O-phtalaldehyde reagent. Rinsho Byori, 20, 291-294. (Japanese)

34) Nakayama, F. (1967) Quantitative microanalysis of bile. J. Lab. clin. Med., 69, 594609.

35) Okawa, H., Hirabayashi, N., Maeda, M., Ueno, K., Matsuoka, S., Asou, S. \& Iwasaki, M. (1976) Effect of ursodeoxycholic acid on bile flow and bile components secretion. Clin. Rep., 10, 40-56. (Japanese)

36) Percy-Robb, I.W., Jalan, K.N., McManus, J.P.A. \& Srucus, W. (1971) Effect of ileal resection of bile salt metabolism in patients with ileostomy following proctocolectomy. Clin. Sci., 41, 371-382.

37) Ponz de Leon, M., Carulli, N., Loria, P., Iori, R. \& Zironi, F. (1980) Cholesterol absorption during bile acid feeding effect of ursodeoxycholic acid administration. Gastroenterology, 78, 214-219.

38) Raicht, R.F., Cohen, B.I. \& Mosbach, E.H. (1974) Effects of sodium taurochenodeoxycholate and taurocholate on cholesterol absorption in the rat. Gastroenterology, 67, 1155-1161.

39) Roda, E., Roda, A., Sama, C., Festi, D., Mazzella, G., Aldini, R. \& Barbara, L. (1979) Effect of ursodeoxycholic acid administration on biliary lipid composition and bile acid kinetics in cholesterol gallstone patients. Digest. Dis. Sci., 24, 123-128.

40) Salvioli, G. \& Salati, R. (1979) Faecal bile acid loss and bile acid pool size during short-term treatment with ursodeoxycholic acid and chenodeoxycholic acid in patients with radiolucent gallstones. Gut, 20, 698-704.

41) Scherstén, T. \& Lindblad, L. (1979) Biliary cholesterol output during ursodeoxycholic acid secretion in man. In: Biological Effects of Bile Acids. edited by G. Paumgartner, 
A. Stiehl \& W. Gerok, MTP Press, Lancaster, England, pp. 53-60.

42) Schwartz, C.C., Berman, M., Vlachevic, Z.R. \& Hollorman, L.G. (1978) Multicompartmental analysis of cholesterol metabolism in man. J. clin. Invest., 61, 408-423.

43) Stiehl, A., Czygan. P., Kommerell, B., Weis, H.J. \& Holtermüller, K.H. (1978) Ursodeoxycholic acid versus chenodeoxycholic acid. Comparison of their effects on bile acid and bile lipid composition in patients with cholesterol gallstones. Gastroenterology, 75, 1016-1020.

44) Stiehl, A., Raedsch, R., Czygan. P., Götz, R., Hänner, C.H., Walker, S. \& Kommerell, B. (1980) Effects of biliary bile acid composition on biliary cholesterol saturation in gallstone patients treated with chenodeoxycholic acid and/or ursodeoxycholic acid. Gastroenterology, 79, 1192-1198.

45) Sugata, F. \& Shimizu, M. (1974) Retrospective studies on gallstone disappearance. Jpn. J. Gastroent., 71, 75-80. (Japanese)

46) Thistle, J.L. \& Hofmann, A.F. (1973) Efficacy and specificity of chenodeoxycholic acid therapy for dissolving gallstones. New Engl. J. Med., 289, 655-659.

47) Thomas, P.J. \& Hofmann, A.F. (1973) A simple calculation for lithogenic index of bile: Expressing biliary lipid composition on rectangular coordinates. Gastroenterology, 65, 698-700.

48) Tokyo Cooperative Gallstone Study Group (1980) Efficacy and indications of ursodeoxycholic acid treatment for dissolving gallstones. A multicenter double-blind trial. Gastroenterology, 78, 542-548. 